\title{
Neonatal thrombocytosis resulting from the maternal use of non-narcotic antischizophrenic drugs during pregnancy
}

\author{
Y Nako, A Tachibana, T Fujiu, T Tomomasa, A Morikawa
}

\begin{abstract}
Neonatal thrombocytosis can result from maternal narcotic drug abuse. The case of a male infant is reported who was born to a woman with schizophrenia treated with non-narcotic psychotropic drugs during pregnancy; he developed severe prolonged thrombocytosis. The platelet count reached $1310 \times 10^{9} / 1$ on day 15 . This thrombocytosis persisted for three months. The patient was treated with dipyridamole. A bone marrow aspirate showed normal myeloid and erythroid precursors with an increased number of megakaryocytes. Plasma concentrations of interleukin 6 and thrombopoietin were suppressed. No obvious complications from the thrombocytosis occurred, and the platelet count fell to within the upper limit of normal after 3 months of age. This case indicates that thrombocytosis may occur in infants born to mothers treated with non-narcotic psychopharmaceutical drugs during pregnancy. The thrombocytosis in this case may have been induced by factors other than interleukin 6 or thrombopoietin.

(Arch Dis Child Fetal Neonatal Ed 2001;84:F198-F200)
\end{abstract}

Keywords: neonatal drug withdrawal syndrome; psychopharmaceuticals; thrombocytosis; thrombopoietin

\section{Case report}

A male infant was delivered vaginally after 35 weeks and five days of gestation. His 25 year old Japanese mother, 0 para 0 gravida, had been diagnosed as having schizophrenia at 23 years of age. She had been treated with psychopharmaceutical drugs (haloperidol 12 $\mathrm{mg}$ /day, biperiden $5 \mathrm{mg} /$ day, promethazine hydrochloride $25 \mathrm{mg} /$ day, nitrazepam $5 \mathrm{mg} /$ day, chlorpromazine $50 \mathrm{mg}$ /day) until the day of delivery. She was not taking opiate illicitly. The pregnancy and delivery were uneventful. Apgar scores were 7 at one minute and 8 at five minutes. Birth weight was $2540 \mathrm{~g}$ (appropriate for date). The baby was admitted to the neonatal ward because of the risk of neonatal drug withdrawal syndrome.

At admission, blood studies were unremarkable. Blood platelet count at birth was $402 \times$ $10^{9} / 1$. For evaluation of possible neonatal drug withdrawal syndrome, we used a scoring system proposed by the Japanese Welfare Ministry and adapted from Finningan et al. ${ }^{1}$ The score for severity of the syndrome peaked at 7 days of age and totalled 7 points, based on decreased muscle tone ( 1 point), tremor on stimulation ( 2 points), vomiting ( 2 points), and poor feeding ( 2 points). The severity decreased gradually, reaching a score of 0 by day 12 without any medication. The baby was fed a regular formula.

The patient's platelet count initially fell to $117 \times 10^{9} / 1$ on day 6 but increased thereafter from $832 \times 10^{9} / 1$ on day 8 to a maximum of $1310 \times 10^{9} / 1$ on day 15 . The result of a platelet adhesion test was $98.8 \%$ (normal range in our laboratory $20-60 \%$ ) on day 15 . Therefore, treatment with dipyridamole (2 $\mathrm{mg} / \mathrm{kg} /$ day) was started on day 15 for prevention of thrombotic complications. A bone marrow aspirate on day 31 of age showed normal myeloid and erythroid precursors with an increased number of megakaryocytes: total cell count, $168333 / \mu \mathrm{l}$; megakaryocyte count, $198 / \mu \mathrm{l}(0.12 \%$; the mean (SD) percentage of megakaryocytes at this age is $0.05(0.09)) .^{2}$ Chromosomal analysis of bone marrow blood showed normal karyotype with no abnormality. Although the haemoglobin concentration decreased to $8.0 \mathrm{~g} / \mathrm{dl}$ on day 38 of life, there was no iron deficiency (serum iron concentration, $69 \mu \mathrm{g} / \mathrm{dl}$ ) and serum erythropoietin concentration was not increased (15.0 $\mathrm{mU} / \mathrm{ml}$ ). Blood thrombopoietin concentration, measured by a sensitive enzyme linked immunosorbent assay, and interleukin 6 (IL6) concentrations, measured by chemiluminescent enzyme immunoassay, were not elevated, but rather depressed; plasma thrombopoietin concentration ranged from 7 to $63.1 \mathrm{pg} / \mathrm{ml}$ (the normal range is $79.9-269.8 \mathrm{pg} / \mathrm{ml}$ at 1 month and $36.9-150.5 \mathrm{pg} / \mathrm{ml}$ at $2-11$ months $^{3}$ ), and serum IL6 concentrations ranged from 0.3 to $5.2 \mathrm{pg} / \mathrm{ml}$ (the normal range is $2.4-10.5 \mathrm{pg} / \mathrm{ml}$ at day 5 and $0.7-11 \mathrm{pg} / \mathrm{ml}$ at day $40^{4}$ ). Serum C reactive protein concentrations were $<0.1$ $\mathrm{mg} / \mathrm{dl}$. After the platelet count decreased to $820 \times 10^{9} / 1$ on day 91 , dipyridamole was stopped. Thereafter, the platelet count decreased further to $600 \times 10^{9} / 1$. However, it remained relatively high, over $400 \times 10^{9} / 1$ after 4 months of age (fig 1). The infant had no symptoms attributable to thrombocytosis. 

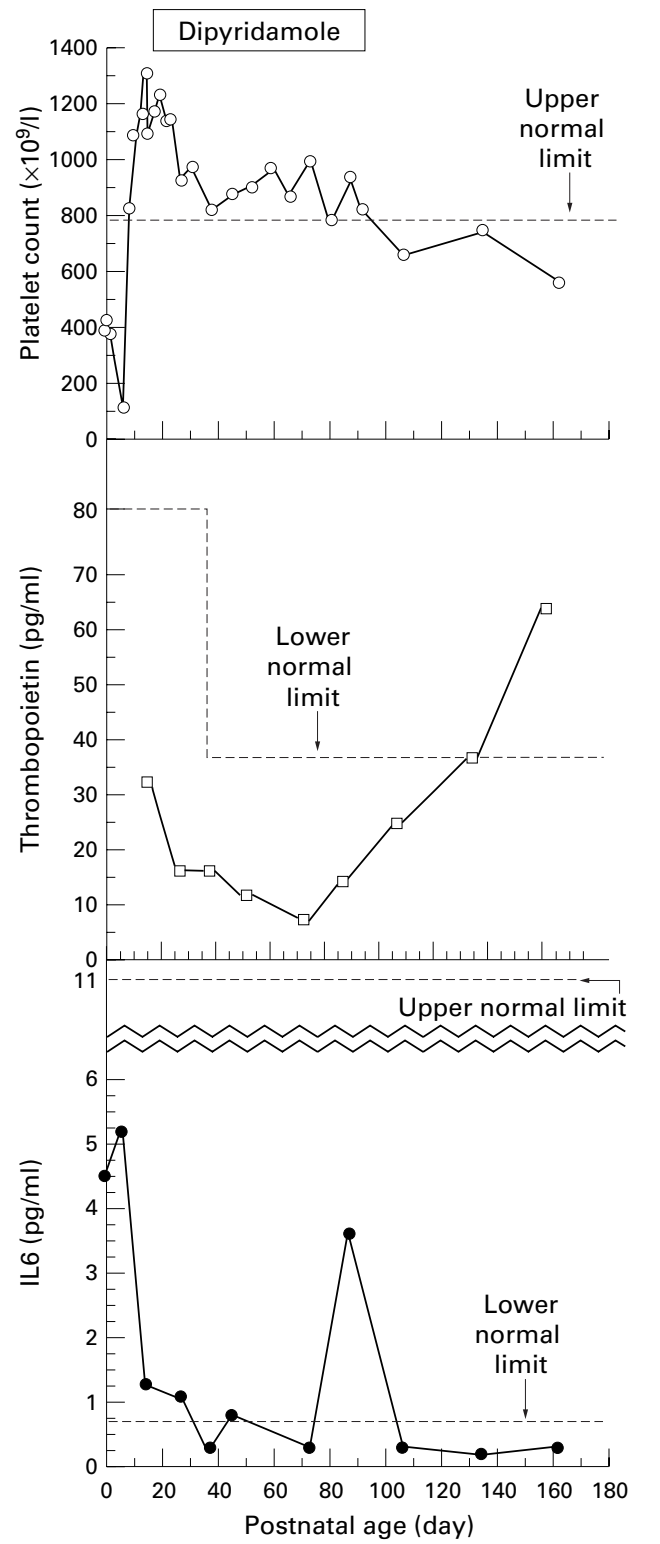

Figure 1 Plasma platelet counts, thrombopoietin, and interleukin 6 (IL6) concentrations of male infant born to mother who used non-narcotic antischizophrenic drugs during pregnancy. The dotted lines represent the upper or lower normal limit for each variable.

Magnetic resonance imaging performed on day 27 of age showed no brain abnormalities, and gross motor development at 1 year of age was normal.

\section{Discussion}

In the neonatal period, essential thrombocytosis is extremely rare, ${ }^{5}$ and most high platelet counts in childhood are the result of secondary thrombocytosis. ${ }^{6-8}$ Maternal drug abuse has been reported to be one cause of secondary thrombocytosis in infants. ${ }^{9-11}$ The drugs in these cases were mostly narcotics.

Thrombocytosis has been reported to occur in the offspring of female mice receiving DL-methadone, ${ }^{12}$ whereas it has not been documented in adult mice or adult humans following the withdrawal of methadone. Interestingly, transient thrombocytosis occurred in five of 24 children who were given an accidental overdose of haloperidol. This occurred 16 days after the final dose of haloperidol. ${ }^{13}$ We speculate that thrombocytosis may occur only in infants and/or children about two weeks after their last exposure to some drugs such as narcotic or psychopharmaceutical drugs, although the detailed mechanism is not known.

Thrombocytosis secondary to maternal drug use usually persists for about 16 weeks. ${ }^{14}$ In our case, a thrombocytosis of over $800 \times 10^{9} / 1$ persisted for about three months, followed by relatively high platelet counts near the upper limit of normal thereafter.

Thrombopoietin is a glycoprotein that primarily regulates megakaryocyte development and platelet production. ${ }^{15}$ It is high during secondary thrombocytosis. ${ }^{16} 17$ In our case, the plasma thrombopoietin concentrations were persistently low during the thrombocytosis, in contrast with those reported in secondary thrombocytosis. However, the report of increased thrombopoietin concentrations preceding thrombocytosis in an inflammatory disorder, Kawasaki disease, ${ }^{18}$ suggests the possibility of increased thrombopoietin concentrations during the prenatal/perinatal period in our patient. Unfortunately, we did not measure plasma thrombopoietin concentrations before 2 weeks of age.

Cytokines other than thrombopoietin, such as IL1, IL-3, IL6, and IL11, stimulate platelet production in vivo. ${ }^{15}$ In secondary thrombocytosis of various causes, serum IL6 and C reactive protein concentrations are often significantly increased. ${ }^{16}{ }^{17}{ }^{19}$ In our case, we found a relatively low plasma IL6 concentration and negative $C$ reactive protein, suggesting that they were not involved in this patient's thrombocytosis. Similarly, serum erythropoietin concentration, which is usually high in iron deficiency anaemia and may contribute to thrombocytosis during human recombinant erythropoietin treatment for anaemia of prematurity, ${ }^{20}$ was not elevated in our patient.

Which of the five drugs prescribed for the mother was the cause of our patient's thrombocytosis? In the report of Burstein et $a l^{9}$ on thrombocytosis in newborn infants of mothers using methadone plus other drugs, all but two mothers used other drugs (diazepam, cocaine, heroin, morphine, amphetamine, and phenobarbital). However, a report on accidental overdosage of haloperidol ${ }^{13}$ was interesting because some children who were given the drug accidentally developed transient thrombocytosis. Apart from this, there are no clues about which of the five drugs were responsible for the thrombocytosis.

1 Finningan LP, Connaughton JF, Emich JP. Neonatal abstinence syndrome: assessment and management. Addict Dis $1975 ; 2: 141-58$

2 Rosse C, Kraemer MJ, Dillon TL, et al. Bone marrow cell populations of normal infants: the predominance of lymphocytes. F Lab Clin Med 1977;89:1225-40.

3 Ishiguro A, Nakahata T, Matsubara K, et al. Age-related changes in thrombopoietin in children: reference interval for serum thrombopoietin levels. $\mathrm{Br} f$ Haematol for serum throm

4 Sarandakou A, Giannaki G, Malamitsi-Puchner A, et al. Inflammatory cytokines in newborn infants. Mediators Inflamm 1998;7:309-12. 
5 Kapoor G, Correa H, Yu LC. Essential thrombocythemia in an infant. F Pediatr Hematol Oncol 1996;18:381-3.

6 Chan KW, Kaikov Y, Wadsworth LD. Thrombocytosis in childhood: a survey of 94 patients. Pediatrics $1989 ; 84: 1064-7$

7 Vora AJ, Lilleyman JS. Secondary thrombocytosis. Arch Dis Child 1993;68:88-90.

8 Sutor AH. Thrombocytosis in childhood. Semin Thromb Hemost 1995;21:330-9.

9 Burstein Y, Giardina PJV, Rausen AR, et al. Thrombocytosis and increased circulating platelet aggregates in newborn infants of polydrug users. 尹 Pediatr 1979;94:895-9.

10 Chabers HM, Haslam RR. Maternal narcotic abuse and neonatal thrombocytosis. Arch Dis Child 1989;64:426.

11 Hanssler L, Claudia R. Erhöhte thrombocytenzahalen bei neugeborenen drogenabhängiger mütter. Klin Pädiatr 1994;206:55-8.

12 Burstein Y, Grady RW, Kreek MJ, et al. Thrombocytosis in the offspring of female mice receiving DL-methadone (40861). Proc Soc Exp Biol Med 1980;164:275-9.

13 Yoshida I, Sakaguchi Y, Matsuishi T, et al. Acute accidental overdosage of haloperidol in children. Acta Paediatr 1993;82:877-80.
14 Burstein Y, Rausen AR, Peterson CM. Duration of thrombocytosis in infants of polydrug (including methadone) users. F Pediatr 1982;100:506.

15 Kaushansky K. Thrombopoietin. $N$ Engl $\mathcal{F}$ Med 1998;339:746-54.

16 Hsu H-C, Tsai W-H, Jiang M-L, et al. Circulating levels of thrombopoietic and inflammatory cytokines in patients with clonal and reactive thrombocytosis. F Lab Clin Med 1999;134:392-7.

17 Verbeek W, Faulhaber M, Griesinger F, et al. Measurement of thrombopoietic levels: clinical and biological relationships. Curr Opin Hematol 2000;7:143-9.

18 Ishiguro A, Ishikita T, Shimbo T, et al. Elevation of serum thrombopoietin precedes thrombocytosis in Kawasaki disease. Thromb Haemostas 1998;79:1096-100.

19 Tefferi A, Ho TC, Ahmann GJ, et al. Plasma interleukin-6 and C-reactive protein levels in reactive versus clonal thrombocytosis. Am $\mathcal{F}$ Med 1994;97:374-8.

20 Donato H, Vain N, Rendo P, et al. Effect of early versus late administration of human recombinant erythropoietin on transfusion requirements in premature infants: results of a randomized, placebo-controlled, multicenter trial. Pediatrics 2000;105:1066-72.

\section{Rapid responses}

Letters on the following papers have been published recently as rapid responses on the ADC website. To read these letters visit www.archdischild.com and click on "read rapid responses":

Dexamethasone treatment and cerebral palsy. P O D Pharoah. Arch Dis Child Fetal Neonatal Ed 2001;84:140.

Neonatal paroxetine withdrawal syndrome. J A Stiskal, N Kulin, G Koren, et al. Arch Dis Child Fetal Neonatal Ed 2001;84:134-5.

Pulse oximetry, severe retinopathy, and outcome at one year in babies of less than 28 weeks gestation. W Tin, D W A Milligan, P Pennefather, et al. Arch Dis Child Fetal Neonatal Ed 2001;84:106-10.

Neonatal meningitis in England and Wales: 10 years on. D E Holt, S Halket, J de Louvois, et al. Arch Dis Child Fetal Neonatal Ed 2001;84:85-9.

Study of maternal influences on fetal iron status at term using cord blood transferrin receptors. D G Sweet, G Savage, T R J Tubman, et al. Arch Dis Child Fetal Neonatal Ed $2001 ; 84: 40-3$.

Muslim birth customs. A R Gatrad, A Sheikh. Arch Dis Child Fetal Neonatal Ed 2001;84:6-8.

Chasing hyponatraemia in preterm infants. S Manzar. Arch Dis Child Fetal Neonatal Ed 2000;83:160.

Normoblasts in large for gestational age infants. S Dollberg, R Marom, F B Mimouni, et al. Arch Dis Child Fetal Neonatal Ed 2000;83:148-9.

Practical management of hyperinsulinism in infancy. A Aynsley-Green, K Hussain, J Hall, et al. Arch Dis Child Fetal Neonatal Ed 2000;82:98-107.

If you would like to post an electronic response to these or any other articles published in the journal, please go to the website, access the article in which you are interested, and click on "eLetters: Submit a response to this article" in the box in the top right hand corner. 